Necropsy.-On opening the abdomen the foctal membranes were found firmly adherent round the abdominal incision, entirely shutting off the peritoneal cavity. Some coils of intestine were acherent around the fintal sac, but there was no sign of any general peritonitis. The uterus corresponded in size to a three months gestation, was somewhat displaced to the left, and contained a well-marked decidual membrane, which was detached and loose in the lower zone, but adherent still above. 'The left ovary and tube were somewhat thickened and matted, but otherwise were normal. 'The right tube was much elongated and continuous at what was apparently its fimbriated end with the foctal sac. The right ovary was represented by a small nodular mass situated at the lower part of the foetal sac. The placenta spread upwards from the pelvis, and the side of the uterus was adherent over the whole right iliac fossa, then passed upwards over the region of the right kidney, and then passed forwards on to the right side of the abdominal wall. The aspect of the peritoneum at the site of attachment was so altered that it was difficult to trace its relations. Numerous vessels passed from the under surface of the placenta to join the neighbouring organs and tissues. The largest vascular connexion to the underlying tissues was a large vein which opened directly into the common iliac vein of that side, and which was necessarily torn across in peeling off the placenta. The placental tissue was healthy throughout, but at the spot where the mass had bulged into the abdominal wound a slough the size of a crown piece was being gradually thrown off. No pus was found anywhere, but low down in the right of the true pelvis, below the placental attachment, there existed a pocket of red grumous fluid amounting to about an ounce and a half, and formed apparently of blood undergoing retrograde change.

liemarks. - In the light of the post-mortem examination it is easy to trace the course and development of this case. Clearly an impregnated ovum became arrested in the ampulla of the right tube, or at all events in the outer part of this tube. As growth proceeded, the Fallopian tube became distended, and probably the membranes of the increasing ovum bulged out from the tube into the peritoneal cavity in the manner described by Mr. Bland Sutton and others. At the time when Mr. Archer Wood was called to see the patient a partial separation of some of the chorionic villi had taken place and internal hæmorrhage had resulted-or, in other words, a tubal miscarriage was threatened. The blood loss and separation were not, however, sufficient to kill the child or to destroy the vitality of the ovum, and so growth proceeded. 'The pain, marked anrmia, and prostration leave very little doubt as to the occurrence of the internal bleeding, and the recurrence in a slighter form of the accident at one week's and again at two weeks' interval renders the probability even greater. The further growth of the ovum dragging up and elongating the involved Fallopian tube and leading to the implication of other neighbouring organs and tissues is just what one might expect. It is interesting to note that, though a marked decidual membrane had been formed insicle the uterus, this was retained throughout the pregnancy and was not thrown off in the early months in the usual way. There was little in the necropsy to explain the cause of death. No general peritonitis existed, no intestinal obstruction, and no collection of pus, and yet the clinical history and temperature chart suggest most strongly that the patient died from some form of blood poisoning. Bearing in mind the existence of a superficial slough on the part of the placenta which bulged into the abdominal wound and was most exposed to the action of microbes, it would seem probable that this was the source and supply of the septic material which poisoned and overpowered the feeble resisting powers of the woman. In all cases of extra-uterine fotation advanced to nearly full term the most important and the most difficult question is the method of dealing with the placenta. The necropsy in this case showed most clearly that any attempt (either primary or secondary) to remove the afterbirth would have led to rupture of the large iliac vein and most certainly to a fatal hæmorrhage. The method which was adopted in the present instance must always expose the patient to the risk of septic poisoning, and I shall not again willingly resort to it. Should another similar case come under my care I shall tie and divide the cord close to the placenta, remove as much of the membranes as may be possible, and then close the abdominal incision entirely, leaving the placenta untouched. There would seem to be no reason why the latter organ, which has rested in the abdomen for some months in vital connexion with surrounding parts, should not continue its existence, gradually undergo retrograde change, and form a quiescent tumour of lowly organised fibroil tissue. It was interesting to note at the operation that the placenta was unusually large and developed; also to observe at the necropsy that the organ was full of dark fluid blood and that no considerable degree of blood-clotting had occurred in the large vascular spaces.

Cavendish-square, $\mathbf{W}$.

\section{THREE SUCCESSFUL SPLENECTOMIES.}

BY J. BLAND SULTON, F.R.C.S. ENG.

ASSISTANT SURGEON TO THE MIDDLESEX HOSPILAI.

Withis the space of six weeks I have performed splenectomy three times, happily in each instance with 2 successful issue. As the cases present features of clinical interest I venture to record them.

CAse 1. Enlarged spleen; recurrent jaundice.-A girl aged seventeen years was placed under my care by Mr. Arthur Wyborn. She was thin and very deeply jaundiced; a large, firm tumour occupied the left half of the abdomen and extended from the costal arch to the pelvis. This tumour exhibited no notches and was dumb to auscultation. There was amenorrhoea of three months' standing, but the pelric organs were normal. The patient stated that since the age of five years a tumour had been known to exist in her "left side" and had never troubled her until the last two years, when she began to experience dragging sensations, accompanied by jaundice. The attacks of jaundice had now become so frequent and she felt so ill that she was incapable of following her vocation. On her admission to the Chelsea Hospital for Women she was put to bed. In a few days the jaundice began to fade and the spleen markedly decreased in size. Dr. Comyns Berkeley estimated the red corpuscles to be $4,500,000$ per cubic millimetre, and the lencocytes were in the proportion of 1 to 122 of the red. Leucocythemia was excluded, and I came to the conclusion that this enlarged spleen became engorged with blood when the patient was up and about, and its drag on the stomach caused kinking of the duodenum and common bile-duct, leading to recurrent jaundice and vomiting. In August, 1895, with the full consent of my colleagues, I exposed the spleen through an incision in the left linea semilunaris. The viscus extended from the diaphragm to the true pelvis, its extremity being in con tact with the uterus. Dr. Giles gently supported the spleen wbilst I secured the slender parts of the gastrosplenic omentum with plaited silk. By the time I was ready to secure the main vessels the viscus had greatly diminished in bulk. There was some anxiety in securing the suspensory ligament, for the dragging necessary to bring it within the sphere of operation produced great interference with respiration. With caution this was successfully overcome and the spleen cut away. I took the opportunity to examine the gall-bladder and found it larger and thicker than usual; the stomach was large and reached below the level of the umbilicus. The wound was secured in triple layers, and the patient returned to bed. She rapidly recovered from shock, quickly convalesced, and left the hos pital with rosy cheeks sixteen days after the operation, feeling, as she expressed it, "remarkably well." The spleen, deprived of blood, weighed two and a half pounds, and on microscopical examination was found to be fairly normal in structure.

CAss 2. Enlarged spleen; ancmia.-Whilst the patient whose case has just been detailed was under observation Mr. Trist and Mr. D. Thurston placed under my care a girl five years of age with an abdominal swelling which they regarded, and rightly, to be an enlarged spleen. The viscus was so large as to extend across the ilio-costal space and dip into the iliac fossa. On palpating its border the charac teristic notches could be felt with great distinotness. Mr. Trist had watched the girl with great interest for many months and had found drugs so useless in this instance that he deemed it necessary to seek the aid of a surgeon The girl was admitted into Middlesex Hospital and carefull watched. Leucocythæmia, rickets, syphilis, and lardaceons disease were excluded. Coming, as this patient did, "on the heels," as it were, of Case 1 , I could scarcely fail to realise 
that I had really to deal with an early stage of the splenic enlargement which was found in that case. After very deliberate consideration and full explanations to the parents, with the assistance of Mr. Leopold Hudson, I deprived this patient of a spleen weighing ten ounces. She recovered in an extraordinary fashion and, thirteen days after the operation, was promenading the ward anci appeared to be the most cheerful inmate of the institution. She is, as far as records show, the youngest child on whom splenectomy has been carried out.

CASE 3. Wandering spleen.-A thin, spare woman thirtytwo years of age, the mother of five children, was placed under the care of Dr. Heywood Smith on account of a mobile tumour in the abdomen. The patient had been aware for ten years that she had a hard, movable body in her abdomen, fout it had become larger and more troublesome during the was made in the left linea semilunaris, and on dipping my hand into the pelvis I recogniserl the spleen in the hollow of the sacrum and drew it forth. The pedicle, rounder, very thick, and hard, was transfixed and secured with four plaited silk ligatures. The detachment of the splcen was followed by an abundant flow of blood, and two forcible but narrow jets of arterial blood issued from the cut surface of the perlicle. The stump was retransfixed with three silk ligatures on the clistal (spleen) side of the first row of sutures, and, as the open, everted mouths of two large arteries were visible on the face of the pedicle, for the security of the patient I ligatured them separately with silk. The pulsations of a large artery in the thick part of the pedicle were unpleasantly obvious as it was allowed to retreat into the abdomen. The wound was secured in triple layers and the patient returned to bed. During the four

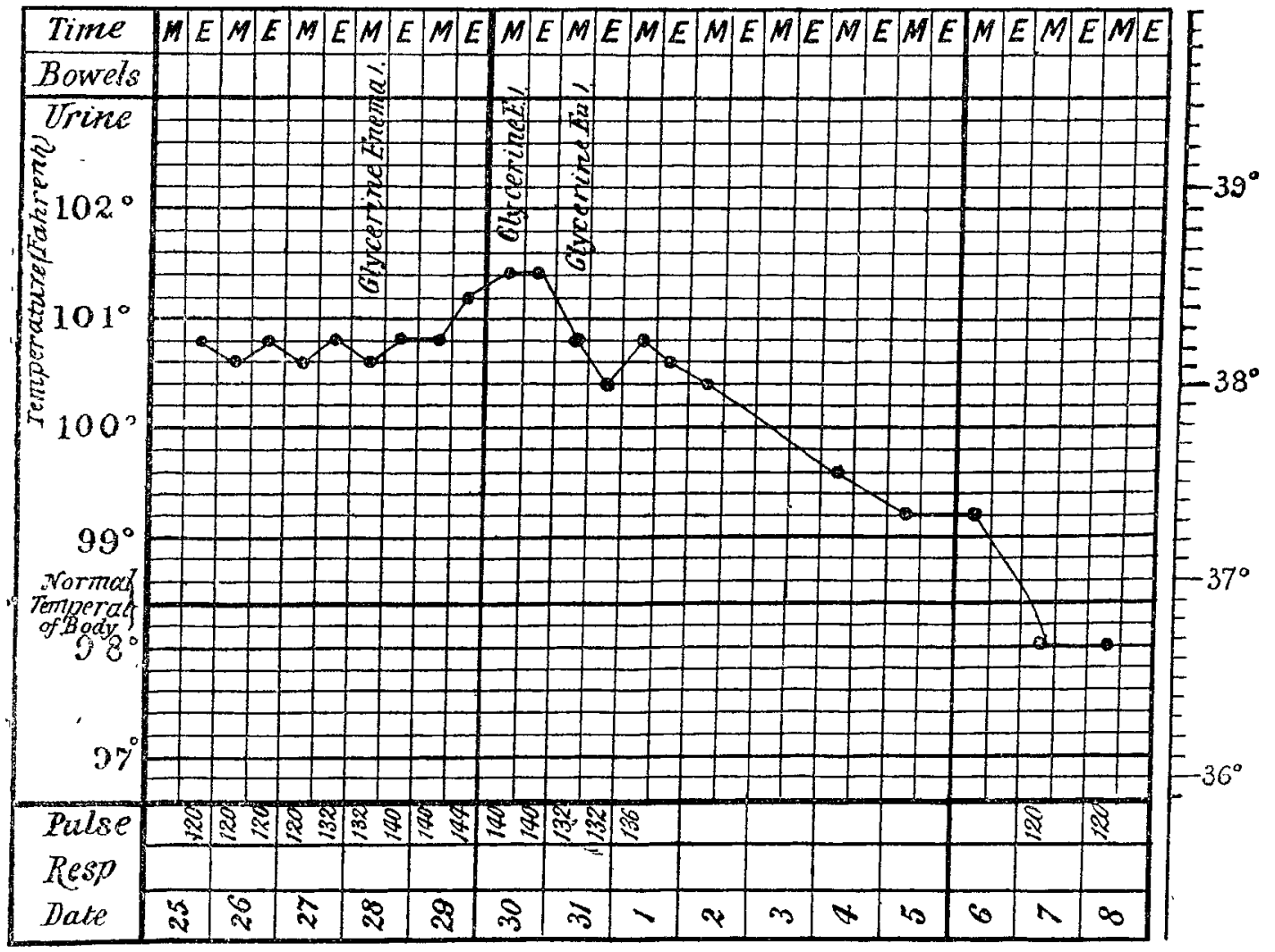

Cast two years. Dr. Heywood Sneith soon satisfied himself / hours subsequent to the operation there were marked signs that the suspected tumour was a spleen, and kindly asked of shock, but no pain; convalescence was astonishingly me to see the patient. At the consultation I found rapid. The spleen weighed eighteen ounces; a splenculus a fairly firm body, in shape like a parabolic mirror, with its convex surface in contact with the anterior wall of the abdomen, floating on the intestines. It could be pushed into the left hypochondrium or clepressed into the hypogastrium; with a little manipulation it could be conveyed into the iliac, lumbar, or umbilical regions. it was clearly a wandering spleen, and is certainly the most prodigal abdominal viscus which has come under my notice. In September, with Dr. Heywood Smith's assistance, I removed this erring organ in the following manner:- When the patient was placed on the operating-table no tumour could be felt with certainty, but I perceived some resisting body when deep pressure was made in the hypogastric region. An incision

\section{THE PATHOLOGICAL CHANGES OF THE LABYRINTH.' \\ BY PROFESSOR POLITYER (OF VIENXA).}

IN seeking an explanation of the various troubles and defects of hearing it is requisite to trace out their causes or, in other words, to ascertain the pathological lesions that occasion them. This paper will, therefore, be devoted to : (1) a review of all the investigations upon these lesions in the labyrinth that have been made by many eminent

1 An arddress delivered at the Fifth International Congress of Otology held at Florence from Sept. 23rd to $26 \mathrm{th}, 1895$. occupied the hilus. Histologically it appeared normal.

The future course of these patients will be watched with great care, but $I$ do not apprebend any evil results. More than three years ago I removed a wandering spleen from a woman twenty-two years of age; she is at the present time in good health, notwithstanding an attack of pleurisy six months ago. I have performed splenectomy four times, and in each case with a satisfactory result. In the early part of this year two other patients were placed under my care for the purpose of splenectomy, but I did not consider them suitable cases for so formidable an operation, for I am convinced that in order to meet with success in splenectomy it is necessary to very carefully select the cases.

Queen Anne-street, W.

observers ; and (2) a statement of personal observations from my own studies in the field of pathological anatomy extending over many years.

Our knowledge of the pathological changes of the labyrinth barely extends beyond the second half of this century. The reason for this scientific hiatus depends mainly upon the imperfection of methods of microscopic examination, which were only successfully remedied about the period indicated, as witnessed by the discovery then made by the illustrious Italian Professor Corti of the histological structure of the cochlea, and the very striking and well-known researche. subsequently undertaken by Böttcher, Moos, Steinbrïgree, Habermann, and others. Nevertheless, many difficulties still exist, such as the impossibility of making post-mortem examinations at once, the meagreness of proofs of labyrinthine affections during life--conditions which hitherto have not enabled us to go beyond the gross anatomical facts of 